\title{
FULLSPECTRUM: a new PV wave making more efficient use of the solar spectrum
}

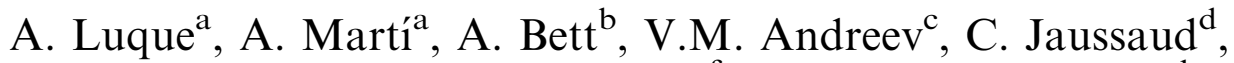
J.A.M. van Roosmalen ${ }^{\text {, }}$ J. Alonso ${ }^{\text {, A. Aäuber }}{ }^{\text {, G. G. Strobl }}{ }^{\mathrm{h}}$, W. Stolz ${ }^{\mathrm{i}}$, C. Algora ${ }^{\mathrm{a}}$, B. Bitnar ${ }^{\mathrm{j}}$, A. Gombert ${ }^{\mathrm{b}}$, C. Stanley ${ }^{\mathrm{k}}$, P. Wahnon ${ }^{\mathrm{a}}$, J.C. Conesa ${ }^{1}$, W.G.J.H.M. van Sark ${ }^{\mathrm{m}, *}$, A. Meijerink ${ }^{n}$, G.P.M. van Klink ${ }^{\mathrm{o}}$, K. Barnham ${ }^{\mathrm{p}}$, R. Danz ${ }^{\mathrm{q}}$, T. Meyer ${ }^{r}$, I. Luque-Heredia ${ }^{\mathrm{s}}$, R. Kenny ${ }^{\mathrm{t}}$, C. Christofides ${ }^{\mathrm{u}}$, G. Sala ${ }^{\mathrm{a}}, \mathrm{P}$ Benítez ${ }^{\mathrm{a}}$

anstituto de Energía Solar-Universidad Politécnica de Madrid IES-UPM, Avda. Ramiro de Maeztu 7 , 28040 Madrid, Spain

${ }^{\mathrm{b}}$ Fraunhofer Institute for Solar Energy Systems (ISE), Heidenhofstr. 2, D-79110 Freiburg, Germany ${ }^{\mathrm{c}}$ Ioffe Physico-Ttechnical Institute, Polytechnicheskaya 26, 194021 St Petersburg, Russia

${ }^{\mathrm{d}}$ Commissariat à l'Energie Atomique, Départment. pour les Technologies des Energies Nouvelles (CEA-DTEN), 17, rue des Martyrs, 38054 Grenoble cedex, France

${ }^{\mathrm{e}}$ Energy Research Centre of the Netherlands ECN, P.O. Box 1, 1755 ZG Petten, Netherlands ${ }^{\mathrm{f}}$ Isofotón S.A., Caleta de Velez 52, 29006 Málaga, Spain

${ }^{\mathrm{g}}$ PSE Projektgesellschaft Solare Energiesysteme mbH, Christaweg 40, D-79114 Freiburg, Germany

${ }^{\mathrm{h}}$ RWE Space Solar Power, Theresienstrasse 2, D-74072 Heilbronn, Germany

${ }^{\mathrm{i}}$ Philipps University of Marburg, Biegenstrasse 10, D-35032 Marburg, Germany

${ }^{\mathrm{j}}$ Paul Scherrer Institute PSI, CH-5232 Villigen, Switzerland

${ }^{\mathrm{k}}$ University of Glasgow, University Avenue, G12 $8 Q Q$ Glasgow, UK

${ }^{1}$ Instituto de Catálisis y Petroleoquímica, Consejo Superior de Investigaciones Cientificas CSIC, Serrano 117, 28006 Madrid, Spain

${ }^{\mathrm{m}}$ Department of Science, Technology and Society, Copernicus Institute, Utrecht University, Heidelberglaan 2, 3584 CS Utrecht, The Netherlands

${ }^{\mathrm{n}}$ Department of Chemistry of Condensed Matter, Debye Institute, Utrecht University, Princetonplein 5, 3584 CC Utrecht, The Netherlands

${ }^{\circ}$ Department of Homogeneous Catalysis and Metal-Mediated Synthesis, Debye Institute, Utrecht University, Padualaan 8, 3584 CH Utrecht, The Netherlands

${ }^{\mathrm{p}}$ Imperial College of Science, Medicine and Technology, Prince Consort Road, SW7 2 BW London, UK ${ }^{\mathrm{q}}$ Fraunhofer Institute for Applied Polymer Research (IAP), Geiselbergstraße 69, 14476 Potsdam, Germany

\footnotetext{
*Corresponding author. Tel.: +31302537611; fax: + 31302537601 .

E-mail address: w.g.j.h.m.vansark@chem.uu.nl (W.G.J.H.M. van Sark).
} 


\author{
${ }^{\mathrm{r}}$ Solaronix SA, Rue de l'Ouriette 129, 1170 Aubonne, Switzerland \\ ${ }^{\mathrm{s}}$ Inspira S.L., Chile 10, 28290 Las Matas, Madrid, Spain \\ ${ }^{\mathrm{t} J o i n t}$ Research Centre, Institute for Environment and Sustainability, Via E. Fermi 1, 21020 Ispra, Italy \\ ${ }^{\mathrm{u}}$ Department of Physics, University of Cyprus, P.O. Box 20537, 1678 Nicosia, Cyprus
}

Received 15 May 2004; received in revised form 5 July 2004; accepted 8 July 2004

Available online 26 November 2004

\begin{abstract}
The project FULLSPECTRUM - an Integrated Project (IP) in the terminology of the European Commission - pursues a better exploitation of the FULL solar SPECTRUM by (1) further developing concepts already scientifically proven but not yet developed and (2) by trying to prove new ones in the search for a breakthrough in photovoltaic (PV) technology. More specific objectives are the development of: (a) III-V multijunction cells (MJC), (b) solar thermo-photovoltaic (TPV) converters, (c) intermediate band (IB) materials and cells (IBC), (d) molecular-based concepts (MBC) for full PV utilisation of the solar spectrum and (e) manufacturing technologies (MFG) for novel concepts including assembling. MJC technology towards $40 \%$ efficiency will be developed using lower cost substrates and high light concentration (up or above 1000 suns). TPV is a concept with a theoretically high efficiency limit because the entire energy of all the photons is used in the heating process and because the non-used photons can be fed back to the emitter, therefore helping in keeping it hot. In the IBC approach, sub-bandgap photons are exploited by means of an IB. Specific IB materials will be sought by direct synthesis suggested by material-band calculations and using nanotechnology in quantum dot (QD) IBCs. In the development of the MBC, topics such as the development of two-photon dye cells and the development of a static global (direct and diffuse) light concentrator by means of luminescent multicolour dyes and QDs, with the radiation confined by photonic crystals, will be particularly addressed. MFG include optoelectronic assembling techniques and coupling of light to cells with new-optic miniconcentrators.
\end{abstract}

(C) 2004 Elsevier B.V. All rights reserved.

Keywords: Photovoltaic energy conversion; Third generation photovoltaics

\title{
1. Introduction
}

The integrated project $^{1}$ (IP) FULLSPECTRUM, funded by the Sixth Framework Programme (FP6) [1] of the European Commission (EC), is oriented towards the development of long-term photovoltaic (PV) technologies and constitutes nothing

\footnotetext{
${ }^{1}$ An integrated project is a new instrument introduced in the Sixth Framework Programme as one of the means to support the creation of a European Research Area. Integrated projects "are designed to give increased impetus to the [European] Community's competitiveness or to address major societal needs by mobilising a critical mass of research and technological development resources and competences" [1]. The first call in the area of sustainable energy systems that have an impact in the medium and longer term has resulted in 14 IPs in which 10-20 research groups collaborate for 5 years with total grants to the budget around 10 million Euros. FULLSPECTRUM is one of the 14 IPs.
} 
less than a revolution in the energy system. This is the opinionof the "Royal Dutch/ Shell Group of Companies" as publicised in their "Energy Needs, Choices and Possibilities - Scenarios to 2050" [2], endorsed in the foreword by Philip Watts, the Chairman of the Committee of Managing Directors:

Two potentially disruptive energy technologies are solar photovoltaics, which offer abundant direct and widely distributed energy, and hydrogen fuel cells, which offer high performance and clean final energy from a variety of fuels. Both will benefit from manufacturing economies but both presently have fundamental weaknesses.

However, the present PV technology will not allow this disruptive future, according also to them. They continue, describing one of its scenarios:

In spite of significant cost improvements, photovoltaic power gains only niche markets...

Since 2025 when the first wave of renewables began to stagnate, biotechnology, materials advances and sophisticated electric network controls have enabled a new generation of renewable technologies to emerge...

By 2050 renewables reach a third of world primary energy and are supplying most incremental energy.

In the FULLSPECTRUM IP, an effort will be made to help this new generation of renewable technologies to emerge. The reason why these technologies are the beginning of this new generation is that they all intend to make more efficient use of the sun's spectrum. While the sun's resource on earth is huge, its power density is however moderate, even less than that of wind in selected locations. Thus, using it is not cheap and appealing high-efficiency conversion technologies must be developed in order to become competitive.

\section{Description of the project FULLSPECTRUM}

The overall goal of this IP is the better exploitation of the solar spectrum in the PV conversion of solar energy. The conventional single semiconductor solar cells only convert photons of energy close to the semiconductor bandgap effectively. Photons with less energy are not absorbed and their energy is totally wasted. Of photons with too much energy, only a fraction of their energy is used.

To overcome this fundamental drawback, this IP has selected five scientific and technological development paths with prospects for accomplishing better exploitation of the solar spectrum and with the potential of eventually being accepted commercially as large diffusion products with the overall aim of providing superior alternatives to today's energy technologies.

As the IP corresponds to a thematic call in the area of research activities in energy having an impact in the medium and longer term, as formulated by the European Commission [3], none of these solutions are commercially implemented yet, but some are ripe for implementation. On the other hand, others are more "blue sky", because 
the goal of this project is to contribute to the advancement not only of the technology but also to the science that will lay down the foundations for future energy technology, beyond the 5-year horizon of this project. Of course, goals reachable within this time-horizon are specified within these areas.

Hence, these five paths are:

(a) the investigation on multi-junction solar cells (MJC)

(b) the investigation into thermophotovoltaics (TPV)

(c) the research into intermediate band solar cells and materials (IBC)

(d) the exploration of molecular-based concepts (MBC)

(e) the research into manufacturing techniques and development of pre-normative work (MFG).

\subsection{Investigation on multi-junction solar cells}

As presented in Fig. 1, monolithic stacks of solar cells are a way of overcoming this fundamental limitation of single junction solar cells. Three solar cells of three different semiconductors appear in this figure. The top cell is made of $\mathrm{Ga}_{0.35} \operatorname{In}_{0.65} \mathrm{P}$ with a larger bandgap of $\sim 1.7 \mathrm{eV}$. This cell converts the most energetic photons. Those photons with energy below the $\mathrm{Ga}_{0.35} \operatorname{In}_{0.65} \mathrm{P}$ bandgap pass to the second $\mathrm{Ga}_{0.83} \mathrm{In}_{0.17}$ As cell where some are converted. The photons with energy below the $\mathrm{Ga}_{0.83} \mathrm{In}_{0.17} \mathrm{As}$ bandgap, of $\sim 1.2 \mathrm{eV}$, pass to the lower cells, made of Ge (bandgap $\sim 0.7 \mathrm{eV}$ ) where they are finally converted. So far the best results, $36.5 \%$ at 100 suns (i.e., AM1.5G, at an irradiance of $10 \mathrm{~W} \mathrm{~cm}^{-2}$ ) has been obtained with an InGaP/ InGaAs/Ge three-junction solar cell by Sharp, NASDA, and the Toyota

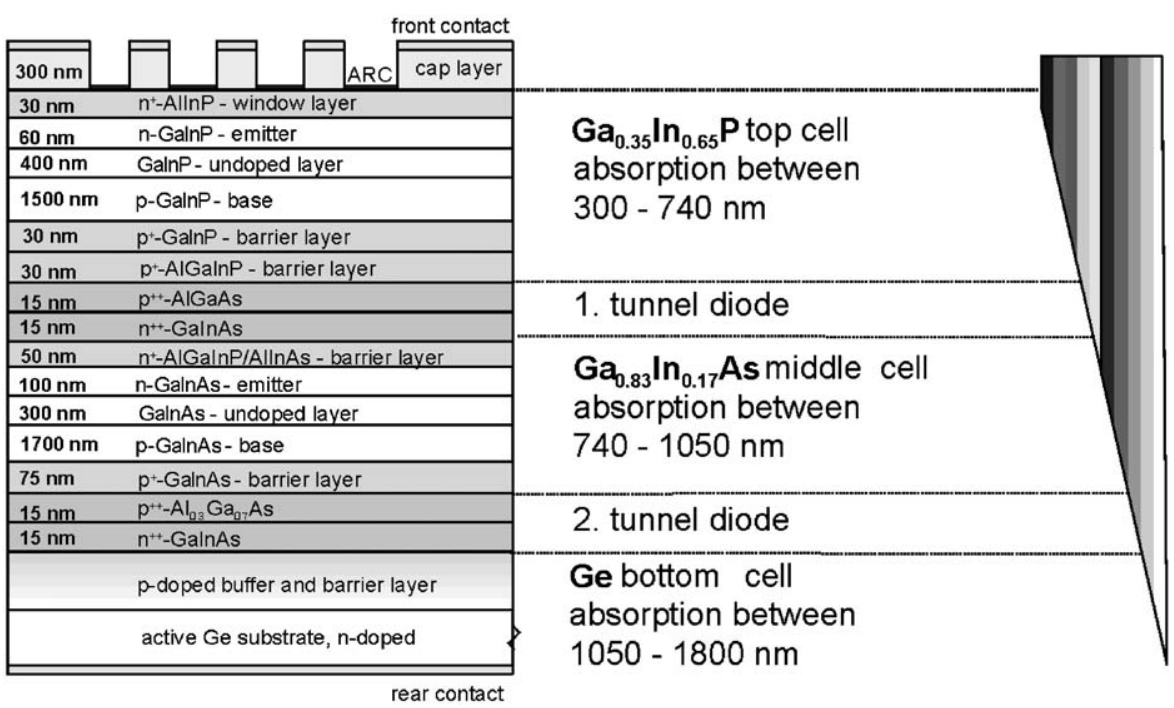

Fig. 1. Example of a structure of a monolithic triple-junction solar cell made of $\mathrm{Ga}_{0.35} \mathrm{In}_{0.65} \mathrm{P}-$, $\mathrm{Ga}_{0.83} \mathrm{In}_{0.17} \mathrm{As}-$ and $\mathrm{Ge}$-junctions interconnected by internal tunnel diodes. 
Technological Institute in Japan [4]. FhG/ISE, one of the project partners, has recently obtained an efficiency of $33.4 \%$ with monolithic $\mathrm{Ga}_{0.35} \mathrm{In}_{0.65} \mathrm{P} / \mathrm{Ga}_{0.83} \operatorname{In}_{0.17} \mathrm{As}$ mechanically stacked on a GaSb cell (bandgaps, 1.7, 1.2, 0.7 eV).

The theoretical potential [5] of this concept is $86.6 \%$, as compared to $40.7 \%$ for the single bandgap semiconductor cell $[6,7]$. Of course, cells reaching this theoretical potential will never be manufactured but this potential shows room for improvement. In fact, in single semiconductor cells, $70 \%$ of their potential has been achieved and exceeding this performance seems very difficult.

MJCs are currently being commercialized in USA for space applications. However, for terrestrial applications they are too expensive. Nevertheless, by using concentrators at high concentration in order to reduce costs (a much lower cell area will be necessary), a commercial version of this type of cell will be developed in this activity.

\subsection{Investigation into thermophotovoltaics}

In a TPV converter, there is a radiator, which becomes incandescent either by solar energy or by fuel combustion. PV cells will convert the radiant power emitted by this artificial radiator into electricity. A schematic diagram is presented in Fig. 2.

In the solar TPV converter, the high efficiency is due to the use of the full spectrum as the radiator presents an absorption pattern close to that of a blackbody. However, the radiation emitted towards the cells is filtered so that only the photons with energy close to and above the cell bandgap will be transmitted. Ideally, the remaining photons will be reflected back to the radiator. Therefore, these photons are not wasted but are absorbed again by the radiator keeping it hot, and its energy will eventually be re-radiated in photons of appropriate energy so as to be effectively converted. The theoretical potential of this concept is $85.4 \%$ [8]. The radiator can also be heated with a fuel, e.g. gas.

This concept has been known since the 1960s but no practical solar TPV converter has ever been manufactured. On the other hand, there is some incipient commercialisation for TPV converters for fuel-heated radiators.

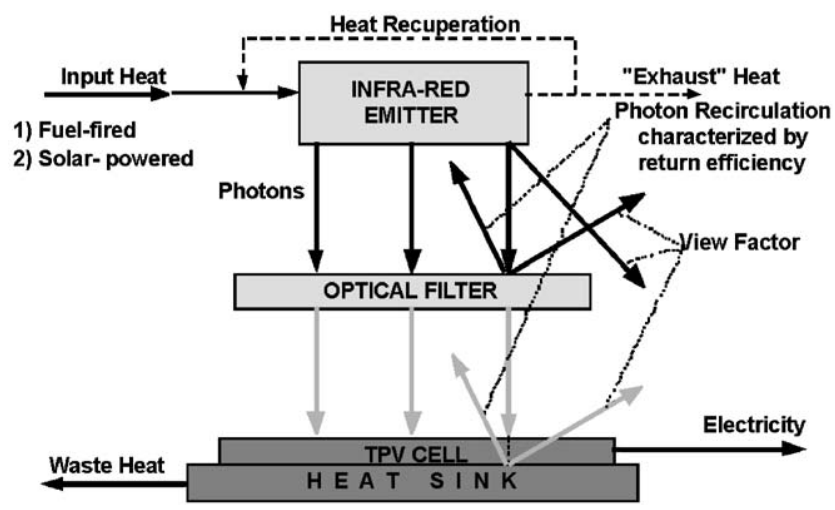

Fig. 2. Principle of TPV conversion. 


\subsection{Research into intermediate band solar cells and materials}

Materials having an intermediate half-filled (or metallic) band in the centre of the semiconductor forbidden band, as represented in Fig. 3, may allow for higher efficiencies in PV conversion due to a better use of the solar spectrum.

In this material, in addition to the conventional promotion of electrons from the valence to the conduction band by absorption of a high-energy photon, also the promotion of electrons from the valence band to the empty states in the intermediate band is possible, or from the full states of this band to the conduction band. In summary, photons from three energy ranges are absorbed without losses, thus making better use of the full solar spectrum. In addition, its energy can be fully recovered to a fraction close to $E_{\mathrm{G}}$. For this, the material must be sandwiched between two layers of an ordinary semiconductor with a bandgap similar to $E_{\mathrm{G}}$. The theoretical potential of this concept is $63 \%$.

The concept was proposed by one of the partners [9] who is developing it with other consortium partners. So far, the sub-bandgap absorption has been demonstrated in a structure based on GaAs sandwiching material, where the IB material is made up of an array of InAs quantum dots (QDs). High voltage output, however, is still to be demonstrated experimentally. Novel structure proposals $[10,11]$ have been proposed which may facilitate the exploitation of this concept.

\subsection{Exploration of molecular-based concepts}

The three-photon effect of the IBC can also, in principle, be implemented by molecular dyes in combination with a semiconductor-electrolyte solar cell thus making again better use of the full spectrum.

The goal in this case is the search for those dye molecules capable of undergoing at least a two-photon operation, i.e., injecting an electron into the conduction band after the consecutive absorption of two photons.

In addition, a line of research will be undertaken in the manufacture of a static concentrator with potential for concentrating diffuse light effectively. A diagram of

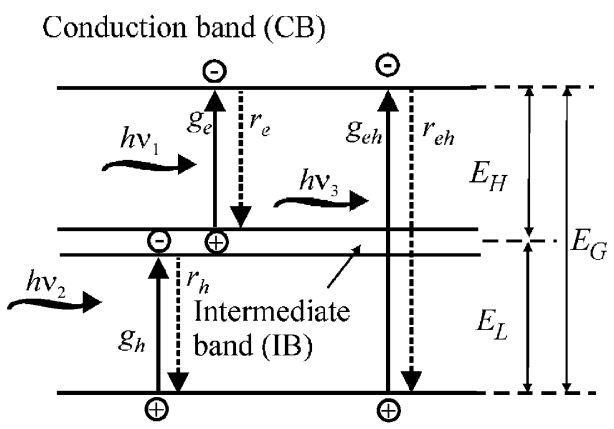

Valence band (VB)

Fig. 3. The principle of the IBC. 
it is shown in Fig. 4. The concentrator consists of a plate of transparent material that contains luminescent dyes of several colours. Sunlight is absorbed by these dyes, which radiate it as luminescent radiation of a given wavelength. This radiation is conducted laterally by the plate towards its edge, where an MJC can be situated capable of converting the different photon energies coming to this edge effectively. Alternatively, as shown in Fig. 4, a prism can separate the colours and cast the light onto individual cells each matched to a given colour. The luminescent dyes can be substituted by QDs. A mirror at the rear and a photonic crystal at the front face assure the effective lateral transportation of the light. Similar to semiconductors with electrons, photonic crystals show forbidden energy gaps for photons. In this way, structures can be envisaged that reflect light in all directions for several narrow wavelength intervals (those of the dyes' luminescence) while transmitting the light in all directions for the rest of the wavelengths.

This very attractive concentrator concept was proposed by Goetzberger and Greubel [12] in the 1970s and was commercialised mainly for small energy applications. The addition of the new photonic crystal concept and the use of QD luminescent centres will expectantly extend the range of practical solutions based on it.

\subsection{Research into manufacturing techniques and development of pre-normative work}

Optical, assembling and tracking techniques appropriate for manufacturing systems with the devices developed in this project will be assured as a result of this activity. For the optical part, several approaches will be analysed by collecting the experience of previous EC funded projects. In particular, non-imaging optics techniques, e.g. as shown in Fig. 5, which aim at transferring radiant energy rather than image formation, will be used. The result will be the use of ultra-flat concentrators resulting in a thickness comparable to that of the flat module. This optics also allows the use of LED-assembling techniques that will probably be

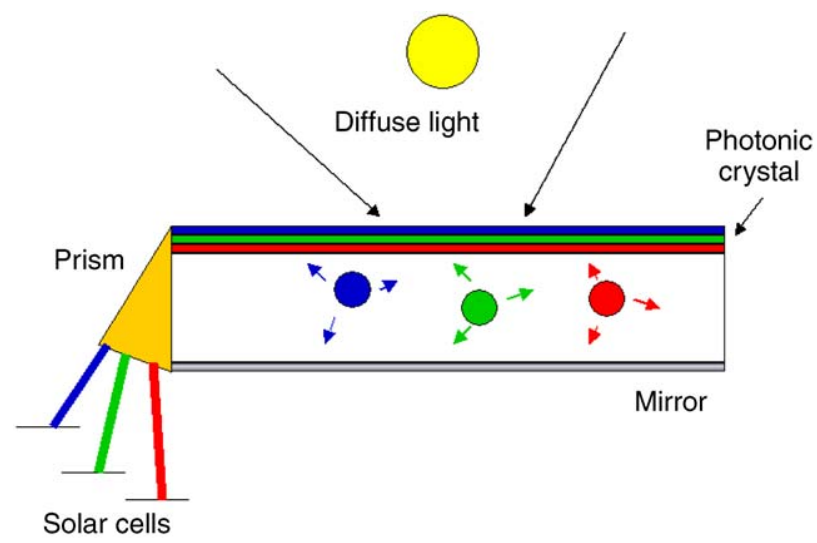

Fig. 4. Luminescent concentrator with photonic crystal. 


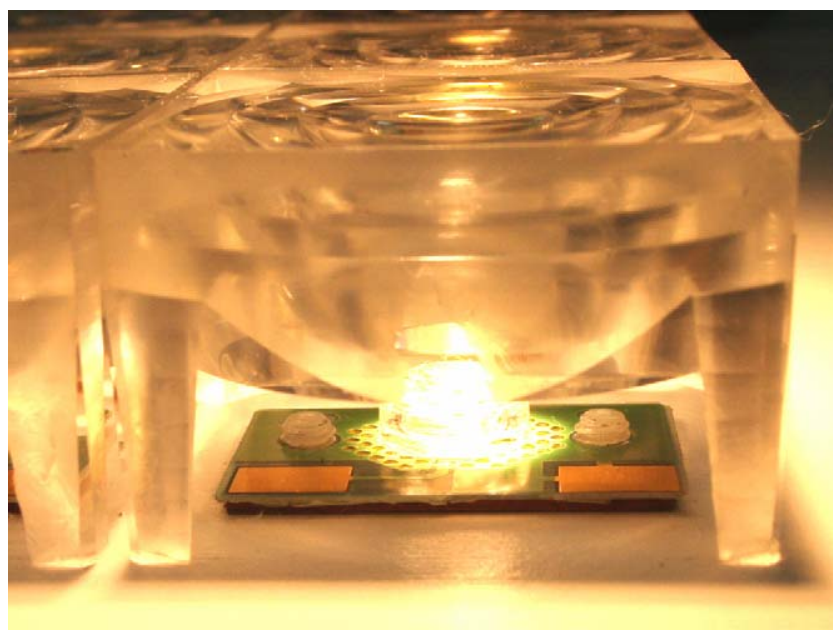

Fig. 5. An example of novel lenses.

extensively used. Luminescent cost-effective flat concentration modules will also be considered as a second alternative, when available. A pre-normative activity will lead to the definition of a standard rating for MJC or other systems that make wider use of the solar spectrum.

\section{Project objectives}

As a general guideline for the development of the five paths described in the previous section, the following objectives have been identified:

1. To progress as much as possible towards the $40 \%$ efficiency goal with the measurable objective of achieving an MJC of at least $35 \%$ efficiency.

2. To develop a solar/fuel prototype TPV capable of operating with solar energy. The measurable objective is the provision of the efficiency of the prototype, which will be as high as possible.

3. To manufacture a full IBC prototype with current-voltage product above those of the solar cells made of the same semiconductor but without the IB structure.

4. Search for those dye molecules capable of undergoing at least a two-photon operation. A natural measure of the success of this objective is to identify such dyes and to show experimentally that they are capable of undergoing the aforementioned two-photon process.

5. To develop a flat concentrator prototype capable of transmitting to the edge with $70 \%$ efficiency in a multi-monochromatic (of at least two colours) radiation receiving light coming from any direction. The measurement of success is the final achievement of the concentrator. 
6. To keep the modularity of the developments made in the project. The measurement of success will be the extent to which a compact concentrator module is developed as well as the appropriate pre-normative being established.

\section{Why this IP can fulfil cost expectations}

Within the Activity Area, "Sustainable development, global change and ecosystems", sub priority, "Sustainable Energy Systems", the European Commission launched a call [3] for proposals under the heading "New and advanced concepts in renewable energy technologies" to which this IP responds. This call stated: "Renewable energy technologies have, in the long term, the potential to make a large contribution to the EU and world energy supply. The main targets are to decrease the cost of electricity and fuel to competitive levels through developing highly efficient concepts" and added, "The main targets are to: decrease the investment cost for PV systems to $1-2 € / \mathrm{Wp}$ (with a module cost of $0.5-1 € / \mathrm{Wp}$ ) by 2015 and to decrease PV electricity cost to below $0.1 € / \mathrm{kWh}$ by 2015 '.

To achieve low costs, one key factor is the learning factor of the technology. It is a well-known economic law that the cost of a product is decreased by a certain factor every time the cumulated sales of this product doubles. For PV modules, most of them made of silicon, this law is represented in Fig. 6 [13].

The cost reduction factor for every doubling of the cumulated sales is 0.8 . This is not a large reduction. For the case of microelectronic memories this factor is 0.68 . The origin of the relatively slow learning factor of the PV modules seems to be the moderate potential for increasing efficiency. The technologies such as the ones of much higher potential efficiency that are proposed here, should decrease the cost reduction factor such that the learning of PV will be much faster. Notice that if the

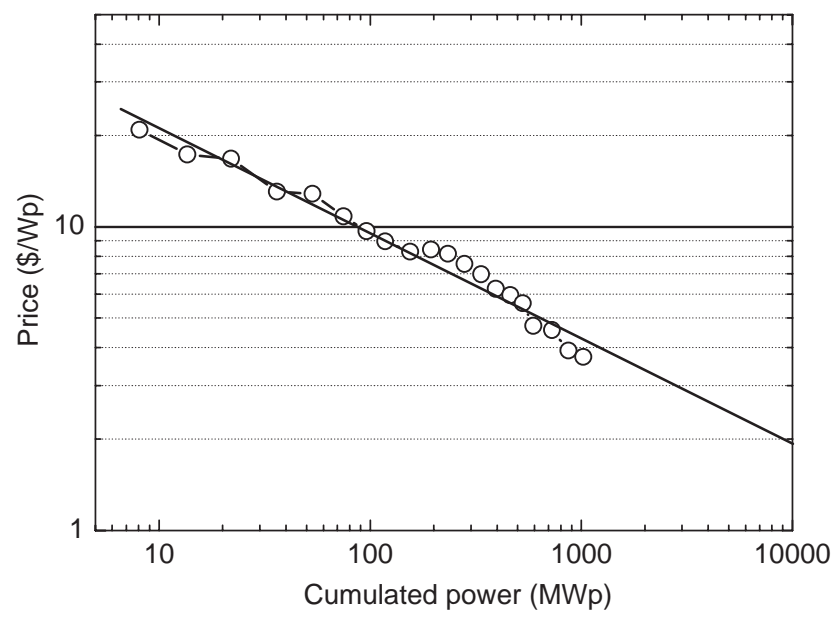

Fig. 6. PV module learning curve, after Luther [13]. 


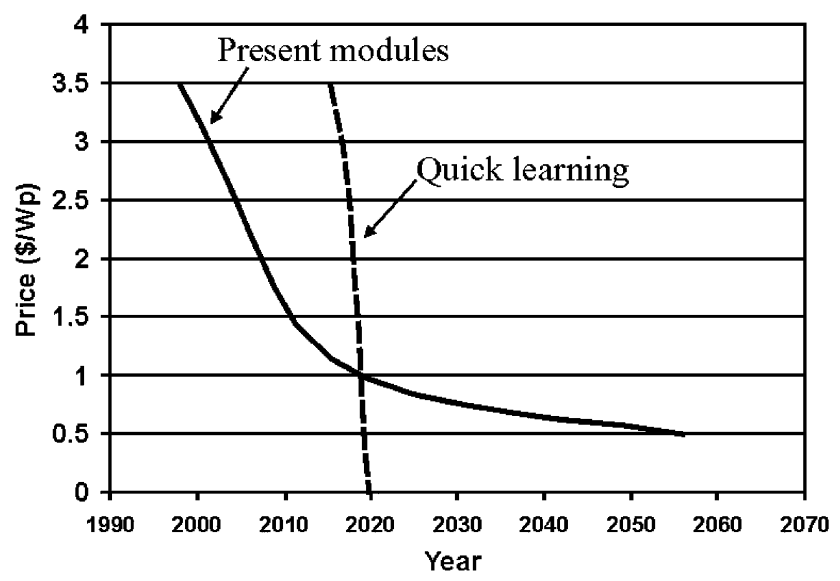

Fig. 7. Price reduction for the present modules and for a new concept with a faster learning factor $(0.68)$ [13].

new product can be sold in spite of its much higher starting price (Fig. 7), in a few years it will have decreased in price drastically [14]. The fact that the price of the new product goes down to zero in the figure is a model artefact and simply means that the PV electricity has become competitive in cost to the current sources of electricity.

Of course, selling a product at such a high price may be difficult and it will become more and more difficult as time progresses and the cost of the modules becomes lower. That is why it is urgent to develop PV solutions with more cost reduction potential. But, indeed, any effort in making the product cheaper will be a great achievement. It is expected that, by 2007 , this cost will allow the development of a market that, given its fast learning factor, will permit the prices to continue to decrease at a very fast pace.

The exercise of making a cost analysis of the technologies proposed here has been carried out on several occasions. The costs of a system based on multijunction solar cells [15] are presented in Table 1. Details of the selection of the parameters are found in the referenced paper [15]. The data in this table suggest that even without the beneficial effect of the learning curve, the EC goal of $0.1 € / \mathrm{kWh}$ may be achieved if the efficiency progression is in line with the project goals $(35 \%$ by 2008 , possibly $45 \%$ by 2015 ).

Regarding the contribution to the advancement of science and technology, the high project scientific-technical content seems clear. It also fulfils most of the political and societal expectancies requested to the renewable energies.

\section{Conclusion}

This paper presents the integrated project FULLSPECTRUM. Its overall goal is the better exploitation of the solar spectrum in the PV conversion of solar energy. 
Table 1

Costs of a very high concentration MJC system, present and future, after Yamaguchi [15].

\begin{tabular}{|c|c|c|c|c|}
\hline & \multicolumn{2}{|c|}{ Medium term } & \multicolumn{2}{|l|}{ Long term } \\
\hline & $1 \mathrm{~J}$ & $2 \mathrm{~J}$ & no learning & learning \\
\hline Substrate wafer $\left(\$\right.$ per $\mathrm{cm}^{2}$ wafer area) & 8.50 & 8.50 & 8.50 & 2.37 \\
\hline Cell processing ( $\$$ per $\mathrm{cm}^{2}$ wafer area) & 4.90 & 7.35 & 7.35 & 2.05 \\
\hline Cells $\left(\$\right.$ per $\mathrm{cm}^{2}$ cell area $)$ & 13.4 & 15.85 & 15.85 & 4.43 \\
\hline Concentration $(X)$ & 1000 & 1000 & 1000 & 1000 \\
\hline Cells $\left(\$\right.$ per $\mathrm{m}^{2}$ aperture area) & 134 & 159 & 159 & 44 \\
\hline \multicolumn{5}{|l|}{ Optics, heat sink and assembling } \\
\hline$\left(\$\right.$ per $\mathrm{m}^{2}$ aperture area $)$ & 131 & 131 & 131 & 69 \\
\hline Module (\$ per aperture area) & 265 & 290 & 290 & 113 \\
\hline Cell efficiency $(\%)$ & 23.1 & 37 & 45 & 45 \\
\hline Optics and interconnection efficiency $(\%)$ & 82.4 & 82.4 & 82.4 & 82.4 \\
\hline Module efficiency $(\%)$ & 19.0 & 30.5 & 37.1 & 37.1 \\
\hline Wp per $\mathrm{m}^{2}$ & 190 & 305 & 371 & 371 \\
\hline Module (\$ per Wp) & 1.39 & 0.95 & 0.78 & 0.31 \\
\hline Area-related BOS ( $\$$ per $\mathrm{m}^{2}$ aperture area) & 114 & 114 & 114 & 60 \\
\hline Power-related BOS (\$ per Wp) & 0.22 & 0.22 & 0.22 & 0.12 \\
\hline BOS ( $\$$ per $\mathrm{m}^{2}$ aperture area) & 156 & 181 & 196 & 104 \\
\hline Plant cost ( $\$$ per $\mathrm{m}^{2}$ aperture $)$ & 421 & 471 & 485 & 217 \\
\hline Mark-up (\%) & 25 & 25 & 25 & 25 \\
\hline Plant price ( $\$$ per $\mathrm{m}^{2}$ aperture area) & 526 & 589 & 607 & 271 \\
\hline Madrid NDI (W m ${ }^{-2} \cdots$ year $\left.^{-1}\right)$ & 1826 & 1826 & 1826 & 1826 \\
\hline Performance ratio & 0.606 & 0.606 & 0.606 & 0.606 \\
\hline Electricity produced $\left(\mathrm{kWh} \mathrm{m}^{-2} \cdots\right.$ year $\left.^{-1}\right)$ & 211 & 337 & 410 & 410 \\
\hline Investment per $\mathrm{kWh}$ produced annually $(\$)$ & 2.50 & 1.74 & 1.48 & 0.66 \\
\hline Return of investment rate $(\%)$ & 6 & 6 & 6 & 6 \\
\hline Years of full amortisation & 30 & 30 & 30 & 30 \\
\hline Annuity for investment (\$ per kWh) & 0.181 & 0.127 & 0.107 & 0.048 \\
\hline Maintenance cost $(\$ \mathrm{~m}-2 \cdots$ year- 1$)$ & 1 & 1 & 1 & 1 \\
\hline Maintenance cost (\$ per kWh) & 0.005 & 0.003 & 0.002 & 0.002 \\
\hline Electricity costs in Madrid ( $\$$ per kWh) & 0.186 & 0.130 & 0.110 & 0.050 \\
\hline \multicolumn{5}{|l|}{ Standard good location (SGL) NDI } \\
\hline$\left(\mathrm{W} \mathrm{m}^{-2} \cdots\right.$ year $\left.^{-1}\right)$ & 2600 & 2600 & 2600 & 2600 \\
\hline Electricity produced $\left(\mathrm{kWh} \mathrm{m}^{-2} \cdots\right.$ year $\left.^{-1}\right)$ & 300 & 480 & 584 & 584 \\
\hline Investment per $\mathrm{kWh}$ produced annually $(\$)$ & 1.75 & 1.22 & 1.04 & 0.46 \\
\hline Annuity for investment ( $\$$ per $\mathrm{kWh})$ & 0.127 & 0.089 & 0.075 & 0.034 \\
\hline Maintenance cost $\left(\$ \mathrm{~m}^{-2} \cdots\right.$ year $\left.^{-1}\right)$ & 1 & 1 & 1 & 1 \\
\hline Maintenance cost ( $\$$ per $\mathrm{kWh})$ & 0.003 & 0.002 & 0.002 & 0.002 \\
\hline Electricity costs in SGL ( $\$$ per $\mathrm{kWh}$ ) & 0.131 & 0.091 & 0.077 & 0.035 \\
\hline
\end{tabular}

Five scientific and technological development paths will be pursued: multijunction solar cells, thermophotovoltaics, intermediate band solar cells and materials, molecular-based concepts (two-photon dyes and flat plate concentrator), and manufacturing techniques and development of pre-normative work. It can be verified that even without the beneficial effect of the learning curve, the EU goal of 
$0.1 € / \mathrm{kWh}$ will be achieved if the efficiency progression stays in line with the project goals $(35 \%$ by 2008$)$.

This project is one of the most ambitious worldwide, if not the most, for developing non-conventional PV approaches. Antecedents are the creation in Australia of the Centre for 3rd Generation Photovoltaics under the direction of Prof. Martin Green, and of programmes such as Beyond the Horizon, set up by the National Renewable Energy Laboratory (NREL) of the United States but these programmes do not include areas such as concentrator-based multijunction solar cells. In USA they are covered by programmes such as high performance PV (managed by NREL) or in Japan, by a similar programme, with goals similar to those in this IP programme. Other options contemplated here, such as solar TPV or diffuse light concentrators probably do not have a match in other programmes.

Institutes and industries from nine European countries (Cyprus, France, Germany, Italy, Russia, Spain, Switzerland, The Netherlands and UK) are involved in the carrying out of this project. This project would be impossible in a nonEuropean dimension.

An active publication policy, in quality journals and selected conferences will be the basis for the dissemination of the scientific parts. The first result of this policy is a special issue of the scientific journal Semiconductors [16] in which the papers published were presented at the EU-Russian Workshop "Efficient Use of the Solar Spectrum in PV" held in St. Petersburg, November 2-5, 2003. A continuously updated website [17] contains public information and information of interest to the partners in the restricted partner area.

\section{Acknowledgements}

The authors gratefully acknowledge the support from the European Commission through the funding of the project FULLSPECTRUM within the sixth Framework Programme under number SES6-CT-2003-502620.

\section{References}

[1] Decision No 1513/2002/EC of the European Parliament and of the Council, Official J. European Commun. L232 (29-08-2002) 1-33.

[2] Shell International, Energy Needs, Choices and Possibilities - Scenarios to 2050, Shell International, 2001.

[3] Call Identifier FP6-2002-Energy-1, Official J. European Commun. C31(5) (17-12-2002) 1-57.

[4] T. Takamoto, T. Agui, K. Kamimura, M. Kaneiwa, M. Imaizumi, S. Matsuda, M. Yamaguchi Multijuction solar cell technologies, Proceedings of the third World Photovoltaic Energy Conversion Conference, Osaka 5 (2003) 581-586.

[5] A. De Vos, H. Pauwels, Appl. Phys. 25 (1981) 119-125.

[6] W. Shockley, H. Queisser, J. Appl. Phys. 32 (1961) 510-519.

[7] G.L. Araújo, A. Martí, Sol. Energy Mater. Sol. Cells 31 (1994) 213-240.

[8] A. Luque, A. Martí, Theoretical limits of photovoltaic conversion, in: A. Luque, S. Hegedus (Eds.), Handbook of Photovoltaic Science and Technology, Wiley, Chichester, 2003, pp. 113-151. 
[9] A. Luque, A. Martí, Phys. Rev. Lett. 78 (1997) 5014-5017.

[10] T. Trupke, M.A. Green, P. Wurfel, J. Appl. Phys. 92 (2002) 4117-4122.

[11] T. Trupke, M.A. Green, P. Wurfel, J. Appl. Phys. 92 (2002) 1668-1674.

[12] A. Goetzberger, W. Greubel, Appl. Phys. 14 (1977) 123-139.

[13] J. Luther, Motivation for photovoltaic application and development, in: A. Luque, S. Hegedus (Eds.), Handbook of Photovoltaic Science and Technology, Wiley, Chichester, 2003, pp. 45-60.

[14] A. Luque, Prog. Photovolt. Res. Appl. 9 (2001) 303-312.

[15] M. Yamaguchi, A. Luque, IEEE Trans. Electron Devices 46 (1999) 2139-2144.

[16] Proceedings of the Symposium on the Efficient Use of Solar Radiation in Photovoltaics Power Engineering, Semiconductors 38 (2004) 899-975.

[17] Website: http://www.fullspectrum-eu.org/. 